\title{
Open Versus Robotic Radical Prostatectomy in Obese Men
}

\author{
Chandy Ellimoottil ${ }^{\mathrm{a}} \quad$ Florian Roghmann ${ }^{\mathrm{b}, \mathrm{c}} \quad$ Robert Blackwell $^{\mathrm{a}} \quad$ Adam Kadlec $^{\mathrm{a}}$ \\ Kristin Greco ${ }^{a}$ Marcus L. Quek ${ }^{\mathrm{a}} \quad$ Maxine Sun $^{\mathrm{b}} \quad$ Quoc-Dien Trinh $^{\mathrm{b}, \mathrm{d}} \quad$ Gopal Gupta $^{\mathrm{a}}$ \\ aLoyola University Medical Center, Maywood, IL., USA; ${ }^{b}$ Cancer Prognostics and Health Outcomes Unit, University of Montreal Health \\ Center, Montreal, Canada; 'Department of Urology, Ruhr University Bochum, Marienhospital, Herne, Germany; ${ }^{\mathrm{d} D i v i s i o n}$ of Urologic \\ Surgery and Center for Surgery and Public Health, Dana-Farber Cancer Institute, Harvard Medical School, Boston, MA., USA
}

\author{
Key Words \\ Obesity • Prostatectomy • Urologic oncology • \\ Prostate cancer $\cdot$ Robotic surgery
}

\begin{abstract}
Objectives: Robotic-assisted radical prostatectomy (RARP) has been shown to reduce blood loss, peri-operative complications and length of stay when compared to open radical prostatectomy (ORP). We sought to determine whether the reported benefits of RARP over ORP translate to obese patients. Patients and Methods: We utilized the 2009-2010 Nationwide Inpatient Sample to identify all obese men with prostate cancer who underwent ORP and RARP. Our primary outcome was the presence of a peri-operative adverse event (i.e. blood transfusion, complication, prolonged length of stay). We fit multivariable logistic regression models to examine whether RARP in obese patients was independently associated with decreased odds of all three outcomes. $\boldsymbol{R} \boldsymbol{e}$ sults: We identified 9,108 obese patients who underwent radical prostatectomy. On multivariable analysis, the use of RARP in the obese population was not independently associated with decreased odds of developing a peri-operative complication (OR =0.81, Cl: 0.58-1.13, p=0.209). RARP was, however, associated with decreased odds of blood transfusion (OR $=0.17, \mathrm{Cl}: 0.10-0.30, \mathrm{p}<0.001)$ and prolonged length of stay (OR $=0.28, \mathrm{Cl}: 0.20-0.40, \mathrm{p}<0.001)$. Conclusion: Our findings suggest that in obese patients, the use
\end{abstract}

\section{KARGER}

Fax +41613061234

E-Mail karger@karger.ch

www.karger.com
(C) 2014 S. Karger AG, Basel

1015-9770/14/0083-0156\$38.00/0

Accessible online at:

www.karger.com/cur of RARP may reduce length of stay and blood transfusions compared to ORP. Both approaches, however, are associated with similar odds of developing a complication.

Copyright $\odot 2014$ S. Karger AG, Basel

\section{Introduction}

With an expected incidence of 233,000 new cases in 2014, prostate cancer is the most common solid organ malignancy in men in the United States [1]. One in six men will develop the disease during their lifetime and many of these men will choose the radical prostatectomy for treatment. In the last decade, the use of robotic-assisted radical prostatectomy (RARP) has surpassed that of open radical prostatectomy (ORP) [2, 3]. Without data from randomized controlled trials, the benefits of RARP over ORP have largely been described using single institution and administrative claims-based studies. Despite the inherent limitations of observational study designs, the evidence suggests that RARP may be associated with decreased blood loss, peri-operative complications, and length of stay [2-4]. 
Obesity affects nearly $40 \%$ of adults in the United States and the operative interventions and perioperative care of these patients can be challenging [5-8]. Comorbid conditions, including diabetes mellitus, hypertension, dyslipidemia, heart disease and obstructive sleep apnea, may increase the risk of adverse peri-operative events and prolong hospital stay [9-11]. Whether the known benefits of RARP translate to the obese population remains largely unknown.

Many previous investigators have studied the clinical and surgical outcomes of obese patients undergoing both RARP and ORP [5, 8, 12-17]. Obese patients are at risk for unfavorable pathologic findings, increased risk of progression towards castrate-resistant disease and increased mortality [18-20]. In single institution studies, obesity has been associated with higher rates of per-operative complications, urinary incontinence, vesico-urethral strictures, and longer operative time when compared with non-obese populations [17, 21, 22]. While single institution studies provide granular patient level data, administrative claims-based analyses allow for the comparison of interventions across hundreds of hospitals and surgeons. Furthermore, large datasets allow for the comparison of rare events (e.g. stroke, acute myocardial infarction).

This study had two objectives. First, we used the Nationwide Inpatient Sample (NIS), an administrative claims-based dataset, to compare three peri-operative adverse events including blood transfusions, complications and prolonged length of stay (pLOS) of obese patients undergoing RARP versus ORP. Second, we used multivariable analysis to determine whether RARP decreased the odds of developing these three adverse events in the obese population.

\section{Patients and Methods}

\section{Dataset}

We used the 2009-2010 NIS for this analysis. Part of the Healthcare Cost and Utilization Project the NIS is maintained by the Agency for Healthcare Research and Quality (AHRQ) and includes all-payer data drawn from hospitals in 44 states. For each year of the dataset, $20 \%$ of participating hospitals are randomly sampled and all discharge data from these selected hospitals are included in that year's dataset. Specifically, hospitals are stratified by state and three-digit zip code and a systematic random sample is drawn to ensure geographic variability and no bias in the type of hospital (e.g. teaching versus non-teaching).

We selected 2009 and 2010 as our study period because, prior to October 2008, robotic procedures could not be distinguished from laparoscopic procedures by using billing codes. We used the methods recommended by Healthcare Cost and Utilization Project to adjust for the sampling used to construct the dataset [23]. The NIS has been widely used by researchers in urology and other surgical fields to compare peri-operative outcomes [2, 24, 25]. Because this study uses publically available data, the study is exempt from institutional review board approval.

\section{Identification of Patient Cohort and Characteristics}

Using International Classification of Disease (ICD), 9th revision, Clinical Modification (ICD-9) procedure and diagnostic codes, we first identified all men with prostate cancer (ICD-9 185.0) who were treated with radical prostatectomy (ICD-9 60.5). Next, if the selected patients had a robotic modifier code (ICD9 17.42) associated with the prostatectomy procedure code, they were categorized in the RARP group. All others were considered as ORP. Finally, we selected only patients who had obesity or morbid obesity listed as a comorbidity. To do so, we used relevant ICD-9 codes that have been previously identified by AHRQ to identify obese patients (ICD-9 278.0, 278.00, 278.01) [26-30]. In addition, we substratified our population according to severity of obesity (morbid obesity ICD-9 278.01). The ICD-9 codes used for obesity are not necessarily associated with a specific body mass index. Patient characteristics included age (category: $\leq 45,46-55$, $56-65,66-75, \geq 76$ years), race (white, black, other) and year of treatment. Median income was classified into four groups: $(1)<$ \$25,000, (2) \$25,000-34,999, (3) \$ 35,000-44,999, and (4) $\geq \$$ 45,000 [19]. Insurance status was based on the expected primary payer, and included Medicare, Medicaid, private insurance, and other (e.g. the uninsured).

We calculated the Charlson Comorbidity Index for each patient using secondary diagnosis codes using a validated algorithm published by Deyo et al. [31] and categorized as $0-1,2, \geq 3$.

\section{Hospital Characteristics}

Hospital characteristics include teaching status, location and hospital volume. Institutional teaching status was obtained from the American Hospital Association Survey of Hospitals. A hospital is considered to be a teaching hospital if it is a member of the Council of Teaching Hospitals; it has an American Medical Association-approved residency program or has a ratio of full-time equivalent interns and residents to beds of 0.25 or higher. Hospital location was defined as urban or rural. Hospital volume was defined according to previously described methodology as the annual number of obese patients with prostate cancer that underwent radical prostatectomy $[32,33]$.

\section{Identification of Outcomes}

Our primary outcomes of interest were blood transfusions, peri-operative complications, and pLOS (length of stay (LOS) $>2$ days). These outcomes were selected because they are commonly used to compare RARP and ORP [2, 3]. We used previously published methodology to identify patients who required a blood transfusion (ICD-9 99.02 and 99.03) and those who had a peri-operative complication [2]. Peri-operative complications were identified using related ICD-9 codes and grouped into categories (any, intraoperative, cardiac, respiratory, gastrointestinal, genitourinary, neurological vascular, infectious, miscellaneous).

LOS is calculated by subtracting the admission date from the discharge date [34]. Same-day stays, coded as 0, were excluded from current analysis. In-hospital mortality information is coded from disposition of patient. Patients with missing or invalid LOS or in-hospital mortality status were not considered within the current study. 
Table 1. Characteristics of obese men undergoing radical prostatectomy

\begin{tabular}{|c|c|c|c|c|c|}
\hline Classification & $\begin{array}{c}\text { ORP } \\
\text { number }\end{array}$ & $\begin{array}{c}\text { ORP } \\
\% \\
\end{array}$ & $\begin{array}{l}\text { RARP } \\
\text { number }\end{array}$ & $\begin{array}{c}\text { RARP } \\
\%\end{array}$ & $\mathrm{p}$ \\
\hline Age (years old) & & & & & 0.014 \\
\hline$<45$ & 32 & 0.9 & 77 & 1.4 & \\
\hline $46-55$ & 710 & 19.7 & 1178 & 21.4 & \\
\hline $56-65$ & 1914 & 53.1 & 2774 & 50.4 & \\
\hline $66-75$ & 934 & 25.9 & 1447 & 26.3 & \\
\hline$>75$ & 11 & 0.3 & 28 & 0.5 & \\
\hline Payer & & & & & $<0.001$ \\
\hline Medicare & 1027 & 28.5 & 1640 & 29.8 & \\
\hline Medicaid & 123 & 3.4 & 121 & 2.2 & \\
\hline Private & 2293 & 63.6 & 3533 & 64.2 & \\
\hline Other & 159 & 4.4 & 204 & 3.7 & \\
\hline Race & & & & & 0.004 \\
\hline White & 2480 & 68.8 & 3786 & 68.8 & \\
\hline Black & 512 & 14.2 & 677 & 12.3 & \\
\hline Other & 613 & 17.0 & 1040 & 18.9 & \\
\hline Median income & & & & & $<0.001$ \\
\hline$<\$ 24,000$ & 808 & 22.4 & 1156 & 21.0 & \\
\hline \$25000-34,999 & 926 & 25.7 & 1447 & 26.3 & \\
\hline$\$ 35,000-44,999$ & 1013 & 28.1 & 1469 & 26.7 & \\
\hline$>\$ 45,000$ & 761 & 21.1 & 1337 & 24.3 & \\
\hline Other & 94 & 2.6 & 94 & 1.7 & \\
\hline CCI & & & & & 0.023 \\
\hline 0 & 2293 & 63.6 & 3340 & 60.7 & \\
\hline 1 & 1103 & 30.6 & 1799 & 32.7 & \\
\hline 2 & 177 & 4.9 & 297 & 5.4 & \\
\hline $3+$ & 32 & 0.9 & 66 & 1.2 & \\
\hline
\end{tabular}

Table compares patient level characteristics of obese patients who underwent radical prostatectomy, stratified by surgical modality. $\mathrm{RARP}=$ Robotic-assisted radical prostatectomy; ORP = open radical prostatectomy.

\section{Statistical Analysis}

Frequencies and proportions were generated for categorical variables; medians and interquartile ranges were generated for continuously coded variables. The Mann-Whitney-U and the Chi-square test were used to assess differences in medians and proportions respectively. We then fit multivariable logistic regression models adjusted for severity of obesity, comorbidity, age, race, median income, insurance status, teaching hospital status, geographic region and HV to examine whether RARP in obese patients was associated with decreased odds of blood transfusion, any peri-operative complication or pLOS. In addition, we adjusted for clustering of patients within hospitals by fitting generalized estimating equations. All tests were two-sided with a statistical significance of $\mathrm{p}<0.05$. Analyses were conducted using SPSS Statistics (Version 20.0, IBM, Chicago, IL) and the R statistical package v.2.13.1 (R Foundation for Statistical Computing).

\section{Results}

We identified 9,108 obese patients (in our weighted population) who underwent radical prostatectomy from January 2009 to December 2010. All of these patients
Table 2. Characteristics of hospitals performing radical prostatectomy

\begin{tabular}{llllll}
\hline Classification & $\begin{array}{c}\text { ORP } \\
\text { number }\end{array}$ & $\begin{array}{c}\text { ORP } \\
\%\end{array}$ & $\begin{array}{c}\text { RARP } \\
\text { number }\end{array}$ & $\begin{array}{c}\text { RARP } \\
\%\end{array}$ & $\mathrm{p}$ \\
\hline Volume & & & & & $<0.001$ \\
$\quad$ Very low & 283 & 39.5 & 152 & 13.9 & \\
$\quad$ Low & 234 & 32.7 & 291 & 26.6 & \\
$\quad$ High & 128 & 17.9 & 291 & 26.6 & \\
$\quad$ Very high & 71 & 9.9 & 362 & 33.0 & \\
Region & & & & & $<0.001$ \\
$\quad$ Northeast & 94 & 13.1 & 190 & 17.3 & \\
$\quad$ Midwest & 179 & 25.0 & 307 & 28.0 & \\
$\quad$ South & 264 & 36.9 & 285 & 26.0 & \\
$\quad$ West & 179 & 9.9 & 314 & 28.6 & \\
Teaching/Location & & & & & $<0.001$ \\
$\quad$ Rural & 44 & 6.1 & 16 & 1.5 & \\
$\quad$ Urban & 238 & 33.2 & 325 & 29.7 & \\
$\quad$ Urban + Teaching & 431 & 60.2 & 755 & 68.9 & \\
$\quad$ 3+ & 0.9 & 0.9 & 1.2 & 1.2 & \\
& & & & &
\end{tabular}

Table compares hospital level characteristics of centers that were included in our study, stratified by surgical modality. RARP $=$ Robotic-assisted radical prostatectomy; ORP $=$ open radical prostatectomy.

Table 3. Peri-operative adverse events observed in obese men undergoing radical prostatectomy

\begin{tabular}{llllll}
\hline Classification & $\begin{array}{c}\text { ORP } \\
\text { number }\end{array}$ & $\begin{array}{c}\text { ORP } \\
\%\end{array}$ & $\begin{array}{c}\text { RARP } \\
\text { number }\end{array}$ & $\begin{array}{c}\text { RARP } \\
\%\end{array}$ & $\mathrm{p}$ \\
\hline Any complication & 156 & 21.6 & 183 & 16.6 & $<0.001$ \\
$\quad$ Intraoperative & 25 & 3.5 & 22 & 2.1 & $<0.001$ \\
Cardiac & 6 & 0.9 & 11 & 1.0 & 0.592 \\
Respiratory & 17 & 2.4 & 20 & 1.7 & 0.040 \\
Gastrointestinal & 19 & 2.6 & 31 & 2.9 & 0.536 \\
Genitourinary & 51 & 7.1 & 68 & 6.1 & 0.049 \\
Neurological & 13 & 1.7 & 17 & 1.5 & 0.516 \\
Vascular & 6 & 0.8 & 8 & 0.7 & 0.574 \\
$\quad$ Infectious & 6 & 0.8 & 3 & 0.3 & $<0.001$ \\
Blood transfusion & 79 & 11.2 & 25 & 2.2 & $<0.001$ \\
Length of stay $>2$ days & 333 & 46.3 & 212 & 19.4 & $<0.001$ \\
Death & 0 & 0 & 0 & 0 & $\mathrm{n} / \mathrm{a}$ \\
& & & & & \\
\hline
\end{tabular}

Table compares adverse events observed in obese men undergoing radical prostatectomy. All comparisons are based on univariate statistical testing. $\mathrm{RARP}=$ Robotic-assisted radical prostatectomy; ORP = open radical prostatectomy.

had obesity $(7,266)$ or morbid obesity $(1,842)$ listed as a comorbidity. For the remainder of the analysis, patients with any form of obesity are referred to as "obese". Among all patients, 5,503 (60.4\%) underwent RARP and $3,605(39.6 \%)$ underwent ORP. Table 1 and 2 describe the main characteristics of our patient cohort and hospitals in our study. 
Table 4. Predictors of peri-operative complications in obese men undergoing radical prostatectomy

\begin{tabular}{llllll}
\hline Variable & Any complication $(\mathrm{CI})$ & $\mathrm{p}$ & Blood transfusion $(\mathrm{CI})$ & $\mathrm{p}$ & Prolonged length of stay $(\mathrm{CI})$ \\
\hline Robotic surgery & $0.81(0.58-1.13)$ & 0.209 & $0.17(0.10-0.30)$ & $<0.001$ & $0.28(0.20-0.40)$ \\
Morbid obesity & $1.61(1.18-2.18)$ & 0.002 & $2.09(1.08-4.05)$ & 0.028 & $1.51(1.05-2.17)$ \\
\hline
\end{tabular}

Table shows selected odds ratios from multivariable logistic regression models. All models incorporated patient level covariates including severity of obesity (morbid versus non-morbid obesity), comorbidity, age, race, median income, insurance status and hospital level covariates including teaching status, geographic region and hospital volume. Of note, the reported results have been adjusted for clustering using generalized estimating equations.

Table 3 describes the rate of organ-specific peri-operative adverse events stratified by RARP and ORP. We found that patients that underwent ORP had a higher rate of any complication occurring compared to those that underwent RARP $(21.3 \%$ vs. $16.6 \%, \mathrm{p}<0.001)$. Specifically, ORP patients had higher rates of intraoperative ( $3.5 \%$ vs. $2.1 \%, \mathrm{p}<0.001)$, respiratory $(2.4 \%$ vs. $1.7 \%$, $\mathrm{p}=0.040)$, genitourinary $(7.1 \%$ vs. $6.1 \%, \mathrm{p}=0.049)$ and infections $(0.8 \%$ vs. $0.3 \%, \mathrm{p}<0.001)$ complications. Obese patients undergoing RARP had decreased rates of pLOS $(46.3 \%$ vs. $19.4 \%, \mathrm{p}<0.001)$ and had a decreased rate of blood transfusion $(11.2 \%$ vs. $2.2 \%, \mathrm{p}<0.001)$.

Selected results from multivariable models are displayed in Table 4. After adjusting for patient and hospital characteristics we found that morbid obesity was independently associated with increased odds of any complication $(\mathrm{OR}=1.61, \mathrm{CI}: 1.18-2.18, \mathrm{p}=0.002)$, blood transfusion $(\mathrm{OR}=2.09, \mathrm{CI}: 1.08-4.05, \mathrm{p}=0.028)$ and pLOS $(\mathrm{OR}=1.51, \mathrm{CI}: 1.05-2.17, \mathrm{p}=0.028)$. The use of robotic surgery in the obese population was not independently associated with decreased odds of any complication $(\mathrm{OR}=0.81, \mathrm{CI}$ : $0.58-1.13, \mathrm{p}=0.209)$. Robotic prostatectomy was, however, associated with decreased odds of blood transfusion (OR $=0.17$, CI: $0.10-0.30, \mathrm{p}<$ $0.001)$ and pLOS (OR $=0.28, \mathrm{CI}: 0.20-0.40, \mathrm{p}<0.001)$.

\section{Discussion}

In this study, RARP was performed more commonly than ORP in obese men. After adjusting for patient and hospital characteristics, we found that obese patients undergoing RARP had reduced odds of having prolonged LOS and receiving a blood transfusion relative to obese patients undergoing ORP. The odds of developing a perioperative complication, however, were similar between obese patients who underwent RARP and ORP. These findings suggest that RARP can be safely performed in obese men and may decrease blood loss and length of stay.

RARP has been previously compared to ORP using secondary data analysis [2-4]. In these studies, RARP has been found to result in fewer peri-operative complications, shorter lengths of stay, and decreased blood loss. Our study builds on this existing evidence by investigating whether the known benefits of RARP translate to a clinically challenging population (i.e. obese men). While we found that previously reported blood loss and LOS benefits of RARP are consistent for obese men, RARP did not reduce the odds of peri-operative complications in this population. Our findings are partially consistent with single institution studies that have evaluated RARP in the obese population $[8,14,16]$. While RARP appears to consistently yield reduced blood loss and length of stay in all studies, RARP reduces the rate of complications in some of these studies. This inconsistency may be partly due to the fact that single institution studies often reflect outcomes of high volume surgeons while a national database captures the outcomes of surgeons across the country with a wide range of experience in robotics.

Our study has several limitations. First, obesity is likely under-coded in administrative claims. Therefore, our results may be biased in an unknown direction by the exclusion of some obese patients. The approach we used to identify obese patients, however, was developed by the U.S. AHRQ. We believe while the AHRQ-defined comorbidity measure for obesity may have not been highly sensitive, it was highly specific for identifying obese patients and has been widely used by researchers in many fields [26-30]. Second, our measure of obesity did not stratify patients by body mass index (BMI). Our dataset did not include height and weight measures, and while ICD-9 modifier codes exist for BMI, these codes are not frequently reported. While using BMI to stratify patients 
may have provided greater nuance to our findings, the use of BMI to define obesity is not without limitations in some patients (e.g. muscular men). Finally, the use of an administrative claims database (i.e. the NIS) to compare interventions has many inherent limitations (e.g. no oncologic information, coding of complications may differ across hospitals, surgeon characteristics and operative time are unknown). Oncological characteristics, such as presence of locally advanced disease or extent of lymph node dissection, will undoubtedly affect perioperative outcomes. Moreover, it is plausible, however, that patients who suffered an adverse event did not have that adverse event coded. For example, if a patient had a blood transfusion, but that transfusion was not coded in their chart, then we would not know if a transfusion was given. There is no way to quantify this misclassification bias that is present in all studies that use administrative claims. The use of a population-based database in the context of this study, however, has advantages over the existing single institution studies. For one, our dataset allows us to compare the two surgical modalities across hospitals and surgeons across the country. Outcomes from single institution studies are often limited to high volume surgeons and centers, which limits their generalizability. Also, rare events are better captured in large datasets. For example, in one single surgeon study com- paring RARP and ORP in obese men, no intraoperative complications and only four total complications were reported in both groups [14].

These limitations notwithstanding, our findings have several implications. For policymakers and payers, the finding that RARP reduces blood transfusion and length of stay even in obese patients offers a better understanding of the value in robotic surgery in challenging patients. For urologists, the finding that ORP and RARP have similar peri-operative complication rates in this subpopulation implies that RARP and ORP remain interchangeable and the surgeon's comfort level with either the procedure should dictate ultimate choice of surgical approach. Finally, for patients with obesity and prostate cancer, the broad findings suggest that both surgical approaches are feasible and safe.

Our collective findings suggest that RARP has a similar complication profile with reduced LOS and blood transfusion rates. Future research in this area should focus on comparing RARP and ORP in regards to oncologic and functional outcomes in obese patients using cancer registries (e.g. surveillance, epidemiology, and end results). Ultimately, the value of RARP in the obese population will depend on a relative balance between peri-operative, oncologic, functional and economic outcomes.

\section{References}

1 Siegel R, Ma J, Zou Z, Jemal A: Cancer statistics, 2014. CA Cancer J Clin 2014;64:9-29.

2 Trinh QD, Sammon J, Sun M, Ravi P, Ghani KR, Bianchi M, Jeong W, Shariat SF, Hansen J, Schmitges J, Jeldres C, Rogers CG, Peabody JO, Montorsi F, Menon M, Karakiewicz PI: Perioperative outcomes of robot-assisted radical prostatectomy compared with open radical prostatectomy: results from the nationwide inpatient sample. Eur Urol 2012;61: 679-685.

3 Hu JC, Wang Q, Pashos CL, Lipsitz SR, Keating NL: Utilization and outcomes of minimally invasive radical prostatectomy. J Clin Oncol 2008;26:2278-2284.

4 Hu JC, Gu X, Lipsitz SR, Barry MJ, D'Amico AV, Weinberg AC, Keating NL: Comparative effectiveness of minimally invasive vs open radical prostatectomy. JAMA 2009;302: 1557-1564.
5 Carter SC, Lipsitz S, Shih YC, Nguyen PL, Trinh QD, Hu JC: Population-based determinants of radical prostatectomy operative time. BJU Int 2014;113:E112-118.

6 Siedhoff MT, Carey ET, Findley AD, Riggins LE, Garrett JM, Steege JF: Effect of extreme obesity on outcomes in laparoscopic hysterectomy. J Minim Invasive Gynecol 2012;19:701-707.

7 Makino T, Shukla PJ, Rubino F, Milsom JW: The impact of obesity on perioperative outcomes after laparoscopic colorectal resection. Ann Surg 2012;255:228-236.

8 Sundi D, Reese AC, Mettee LZ, Trock BJ, Pavlovich CP: Laparoscopic and robotic radical prostatectomy outcomes in obese and extremely obese men. Urology 2013;82:600605.
9 Ogden CL, Carroll MD, Kit BK, Flegal KM: Prevalence of obesity among adults: United States, 2011-2012. NCHS Data Brief 2013; 131:1-8.

10 Berrington de Gonzalez A, Hartge P, Cerhan JR,Flint AJ, Hannan L, MacInnis RJ, Moore SC, Tobias GS, Anton-Culver H, Freeman LB, Beeson WL, Clipp SL, English DR, Folsom AR, Freedman DM, Giles G, Hakansson N, Henderson KD, Hoffman-Bolton J, Hoppin JA, Koenig KL, Lee IM, Linet MS, Park Y, Pocobelli G, Schatzkin A, Sesso HD, Weiderpass E, Willcox BJ, Wolk A, Zeleniuch-Jacquotte A, Willett WC, Thun MJ: Bodymass index and mortality among 1.46 million white adults. N Engl J Med 2010;363:22112219.

11 Abir F, Bell R: Assessment and management of the obese patient. Crit Care Med 2004;32(4 suppl):S87-91. 
12 Kaneko G, Miyajima A, Yuge K, Hasegawa M, Takeda T, Jinzaki M, Kikuchi E, Nakagawa K, Oya M: Periprostatic fat area is an independent factor that prolonged operative time in laparoscopic radical prostatectomy. Urology 2013;82:1304-1309.

13 Gacci M, Sebastianelli A, Salvi M, De Nunzio C, Schiavina R, Simonato A, Tubaro A, Mirone V, Carini M, Carmignani G: Role of abdominal obesity for functional outcomes and complications in men treated with radical prostatectomy for prostate cancer: results of the Multicenter Italian Report on Radical Prostatectomy (MIRROR) study. Scand J Urol 2014;48:138-145.

14 Abdul-Muhsin H, Giedelman C, Samavedi S, Schatloff O, Coelho R, Rocco B, Palmer K, Ebra G, Patel V: Perioperative and early oncological outcomes after robot-assisted radical prostatectomy (RARP) in morbidly obese patients: a propensity score-matched study. BJU Int 2014;113:84-91.

15 Tomaszewski JJ, Chen YF, Bertolet M, Ristau BT, Woldemichael E, Nelson JB: Obesity is not associated with aggressive pathologic features or biochemical recurrence after radical prostatectomy. Urology 2013;81:992996.

16 Bae JJ, Choi SH, Kwon TG, Kim TH: Advantages of robot-assisted laparoscopic radical prostatectomy in obese patients: comparison with the open procedure. Korean J Urol 2012; 53:536-540.

17 Wolin KY, Luly J, Sutcliffe S, Andriole GL, Kibel AS: Risk of urinary incontinence following prostatectomy: the role of physical activity and obesity. J Urol 2010;183:629-633.

18 Keto CJ, Aronson WJ, Terris MK, Presti JC, Kane CJ, Amling CL, Freedland SJ: Obesity is associated with castration-resistant disease and metastasis in men treated with androgen deprivation therapy after radical prostatectomy: results from the SEARCH database. BJU Int 2012;110:492-498.
19 Parker AS, Thiel DD, Bergstralh E, Carlson RE, Rangel LJ, Joseph RW, Diehl N, Karnes RJ: Obese men have more advanced and more aggressive prostate cancer at time of surgery than non-obese men after adjusting for screening PSA level and age: results from two independent nested case-control studies. Prostate Cancer Prostatic Dis 2013;16:352356.

20 Allott EH, Masko EM, Freedland SJ: Obesity and prostate cancer: weighing the evidence. Eur Urol 2013;63:800-809.

21 Van Roermund JG, van Basten JP, Kiemeney LA, Karthaus HF, Witjes JA: Impact of obesity on surgical outcomes following open radical prostatectomy. Urol Int 2009;82:256261.

22 Wiltz AL, Shikanov S, Eggener SE, Katz MH, Thong AE, Steinberg GD, Shalhav AL, Zagaja GP, Zorn KC: Robotic radical prostatectomy in overweight and obese patients: oncological and validated-functional outcomes. Urology 2009;73:316-322.

23 Healthcare Cost and Utilization Project. http://www.hcup-us.ahrq.gov/toolssoftware/ ccs/ccs.jsp\#download. Accessed 1/18/2015.

24 Hall EC, Boyarsky BJ, Deshpande NA, Garonzik-Wang JM, Berger JC, Dagher NN, Segev DL: Perioperative complications after live-donor hepatectomy. JAMA Surg 2014; 149:288-291.

25 Yu HY, Hevelone ND, Lipsitz SR, Kowalczyk KJ, Nguyen PL, Choueiri TK, Kibel AS, $\mathrm{Hu}$ JC: Comparative analysis of outcomes and costs following open radical cystectomy versus robot-assisted laparoscopic radical cystectomy: results from the US Nationwide Inpatient Sample. Eur Urol 2012;61:12391244.

26 Weiss AJ, Elixhauser A: Obesity-Related Hospitalizations, 2004 versus 2009: Statistical Brief \#137. Agency for Health Care Policy and Research (US). 2006 Feb-2012 Jul.
27 Dhoot J, Tariq S, Erande A, Amin A, Patel P, Malik S: Effect of morbid obesity on in-hospital mortality and coronary revascularization outcomes after acute myocardial infarction in the United States. Am J Cardiol 2013;111: 1104-1110.

28 Lee J, Mabardy A, Kermani R, Lopez M, Pecquex N, McCluney A: Laparoscopic vs open ventral hernia repair in the era of obesity. JAMA Surg 2013;148:723-726.

29 Odum SM, Springer BD, Dennos AC, Fehring TK: National obesity trends in total knee arthroplasty. J Arthroplasty 2013;28(8 suppl):148-151.

30 Mason RJ, Moroney JR, Berne TV: The cost of obesity for nonbariatric inpatient operative procedures in the United States: national cost estimates obese versus nonobese patients. Ann Surg 2013;258:541-551.

31 Deyo RA, Cherkin DC, Ciol MA: Adapting a clinical comorbidity index for use with ICD9-CM administrative databases. J Clin Epidemiol 1992;45:613-619.

32 Liu JH, Zingmond DS, McGory ML, SooHoo NF, Ettner SL, Brook RH, Ko CY: Disparities in the utilization of high-volume hospitals for complex surgery. JAMA 2006;296:19731980.

33 Trinh QD, Sun M, Sammon J, Bianchi M, Sukumar S, Ghani KR, Jeong W, Dabaja A, Shariat SF, Perrotte P, Agarwal PK, Rogers CG, Peabody JO, Menon M, Karakiewicz PI: Disparities in access to care at high-volume institutions for uro-oncologic procedures. Cancer 2012;118:4421-4426.

34 Sun M, Abdollah F, Shariat SF, Schmitges J, Trinh QD, Tian Z, Jeldres C, Abdo A, Bianchi M, Briganti A, Montorsi F, Perrotte P, Karakiewicz PI: Propensity-score matched comparison of complications, blood transfusions, length of stay, and in-hospital mortality between open and laparoscopic partial nephrectomy: a national series. Eur J Surg Oncol 2012;38:80-87. 